\title{
Secondary Adrenal Insufficiency Due to the Co-Administration of Ritonavir and Inhaled Fluticasone Propionate Case report
}

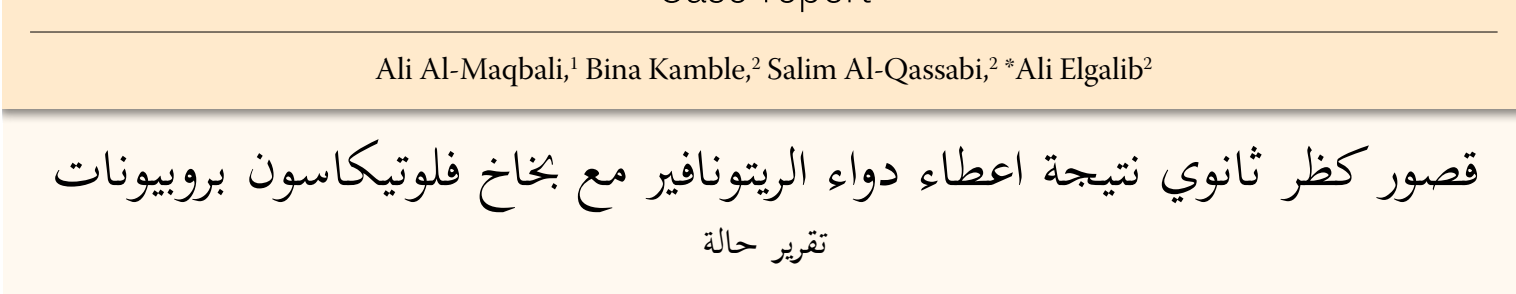

علي المقبالي، بينا كامبل، سالم القصابي، علي الجالب

ABSTRACT: Ritonavir is a powerful inhibitor of the cytochrome P450 3A4 (CYP3A4) isoenzyme. It is used as a pharmaceutical enhancer in the management of HIV-positive patients. However, when co-administered with other drugs that are metabolised via the CYP3A4 pathway, ritonavir can potentially cause serious drug-drug interactions. Inhaled fluticasone propionate, which is used to treat asthma and chronic obstructive airway disease, is particularly prone to such interactions due to its physiological attributes. We report a HIV-positive 48-year-old male patient who presented to Al Nahdha Hospital, Muscat, Oman, in 2012 with weight loss, generalised weakness and fatigue and diagnosed with secondary adrenal insufficiency as a result of concomitant ritonavir and inhaled fluticasone.

Keywords: Human Immunodeficiency Virus; Ritonavir; Fluticasone; Drug Interactions; Adrenal Insufficiency; Case Report; Oman.

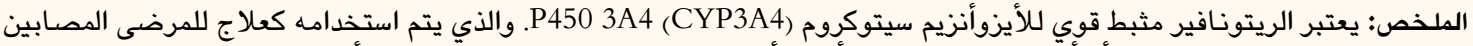

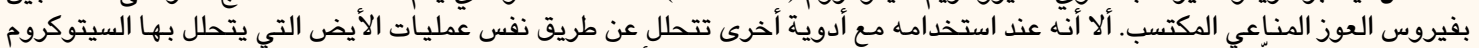

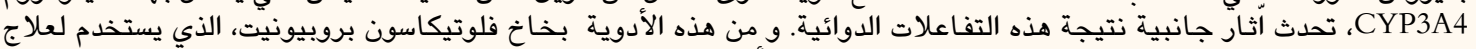

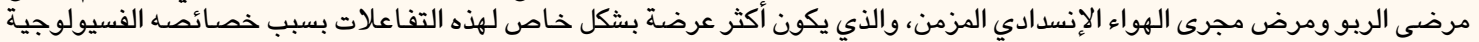

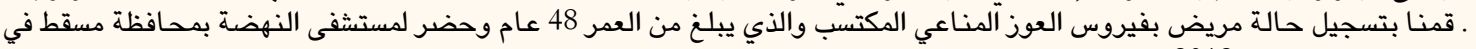

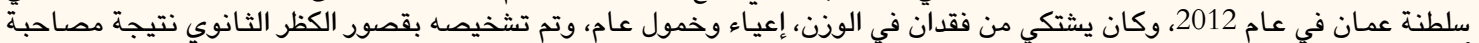

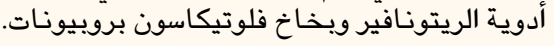

الكلمات المفتاحية؛ فيروس العوز المناعي المكتسب؛ الريتونافير؛ فلوتيكاسون؛ تفاعلات أدوية؛ قصور الكظر؛ حالة مرضية؛ عمان.

$\mathrm{T}$ HE USE OF HIGHLY-ACTIVE ANTIRETROVIRAL therapy (HAART) has revolutionised the prognosis of HIV-infected patients and ensured that the infection remains a treatable chronic condition. With prompt diagnosis and treatment, HIVinfected individuals now have a life expectancy similar to that of the general population. ${ }^{1}$ Ritonavir, a powerful inhibitor of the cytochrome P $4503 \mathrm{~A} 4$ (CYP3A4) isoenzyme, is often prescribed once daily in small doses to HIV patients as a pharmacokinetic enhancer of protease inhibitors. ${ }^{2}$ This allows the use of fewer protease inhibitor tablets, hence improving patient compliance and increasing the potency of HAART. ${ }^{3}$ However, harmful interactions can occur when ritonavir is co-administered with other drugs that are metabolised via the CYP3A4 pathway, such as corticosteroids, macrolides and statins. ${ }^{3,4}$
Fluticasone propionate is an inhaled steroid used to manage chronic obstructive airway disease and asthma and is a substrate of the CYP3A4 enzyme similar to beclomethasone, budesonide and triamcinolone. ${ }^{5}$ However, fluticasone propionate is more likely to interact with CYP3A4 inhibitors due to its longer half-life, higher glucocorticoid receptorbinding affinity, greater lipophilicity and larger volume distribution. ${ }^{5}$ A pharmacokinetic study of healthy volunteers found that ritonavir increased the area under the curve of serum fluticasone by 350 -fold. ${ }^{6}$ This case report describes the development of secondary adrenal insufficiency in an HIV-positive patient as a result of the concomitant administration of ritonavir and inhaled fluticasone propionate. 


\section{Case Report}

A 48-year-old man presented to the HIV clinic of $\mathrm{Al}$ Nahdha Hospital, Muscat, Oman, in 2012 for a routine check-up. He had initially been diagnosed with an asymptomatic HIV infection in 1999 with a baseline cluster of differentiation (CD) 4 count of $>200$ cells $/ \mathrm{mL}^{3}$. At the time of diagnosis, his only comorbidity was bronchial asthma. Subsequently, the patient had developed an atypical mycobacterial infection in 2008 after which HAART was initiated in the form of $150 \mathrm{mg}$ of lamivudine and $300 \mathrm{mg}$ of zidovudine twice a day and $600 \mathrm{mg}$ of efavirenz once a day. Six months later, due to virological failure, his medication regimen was changed to $400 \mathrm{mg}$ of oral didanosine once a day and $40 \mathrm{mg}$ of oral stavudine and $800 / 100 \mathrm{mg}$ of oral ritonavir-boosted indinavir/ritonavir twice a day. This resulted in a satisfactory immunological response and complete viral load suppression. However, due to intolerance, these antiretroviral (ARV) drugs were again changed in 2010 to $150 \mathrm{mg}$ of oral lamivudine, $300 \mathrm{mg}$ of oral abacavir and 400/100 $\mathrm{mg}$ of oral lopinavir/ritonavir twice a day. From 1999 until 2007, the patient also took $200 \mu \mathrm{g}$ of inhaled salbutamol as required and $100 \mu \mathrm{g}$ of inhaled beclomethasone twice a day for his asthma. In 2008, the beclomethasone was substituted for $250 \mu \mathrm{g}$ of inhaled fluticasone propionate twice a day.

At presentation, the patient reported a twomonth history of weight loss, generalised weakness and fatigue. His vital signs were normal apart from low blood pressure $(90 / 60 \mathrm{mmHg})$. His examination results were unremarkable, with no signs of Cushing's syndrome or lipodystrophy. Routine investigations, including a complete blood count and urea, electrolyte, liver function, thyroid function and lipid profile tests, were all within normal limits. His CD4 count was 425 cells $/ \mathrm{mL}^{3}$ and the HIV viral load was $<20$ copies/mL.

Table 1: Serial basal and stimulated cortisol and adrenocorticotropic hormone levels of a HIV-positive 48-year-old male patient with secondary adrenal insufficiency

$\begin{array}{lccc} & \begin{array}{c}\text { Basal } \\ \text { cortisol } \\ \text { level in } \\ \text { nmol/L }\end{array} & \begin{array}{c}\text { Stimulated* } \\ \text { cortisol } \\ \text { level in } \\ \text { nmol/L }\end{array} & \begin{array}{c}\text { Serum } \\ \text { ACTH in } \\ \mathbf{p g} / \mathbf{m L}\end{array} \\ \text { At presentation } & 7 & 71 & 5.4 \\ 1 \text { month later } & 11 & - & - \\ 8 \text { months later } & 136 & - & - \\ 11 \text { months later } & 317 & - & 43.1 \\ 16 \text { months later } & 390 & 880 & - \\ \text { ACTH = adrenocorticotropic hormone. } & \end{array}$

At baseline, his morning serum cortisol levels were $7 \mathrm{nmol} / \mathrm{L}$ (normal range: $200-550 \mathrm{nmol} / \mathrm{L}$ ) on two occasions and his plasma adrenocorticotropic hormone $(\mathrm{ACTH})$ level was $5.4 \mathrm{pg} / \mathrm{mL}$ (normal range: $7-50 \mathrm{pg} / \mathrm{mL}$ ). One hour after administrating $250 \mu \mathrm{g}$ of synthetic ACTH, his cortisol level increased to $71 \mathrm{nmol} / \mathrm{L}$. Levels of other pituitary hormones, plasma sodium and potassium were within normal limits.

A diagnosis of secondary adrenal insufficiency was made. The administration of inhaled fluticasone propionate was immediately halted and the patient was instead prescribed $20 \mathrm{mg}$ of oral hydrocortisone in two divided doses per day. Within four weeks, symptoms of weakness and fatigue had dramatically improved; moreover, the asthma symptoms did not worsen and the patient continued using $200 \mu \mathrm{g}$ of inhaled salbutamol as required. Following the fluticasone withdrawal, basal cortisol levels were $136 \mathrm{nmol} / \mathrm{L}$ and $317 \mathrm{nmol} / \mathrm{L}$ at 8 and 11 months, respectively. His ACTH level was $43.1 \mathrm{pg} / \mathrm{mL}$ at 11 months. After a period of one year, the hydrocortisone dose was tapered successfully over a three month period. Finally, one month after the hydrocortisone was discontinued, the patient's response to synthetic ACTH was normal. Table 1 shows the patient's serial basal and stimulated cortisol levels and plasma ACTH levels over time.

\section{Discussion}

Previous research has indicated that the concomitant use of inhaled fluticasone propionate and ritonavir leads to the systemic accumulation of fluticasone, consequently causing iatrogenic Cushing's syndrome and secondary adrenal insufficiency. ${ }^{7-14}$ In a recent literature review, Epperla et al. reported a total of 37 cases of iatrogenic Cushing's syndrome and adrenal suppression as a result of concomitant use of fluticasone and ritonavir in which the time between co-administration and the development of symptoms ranged from two weeks to two years. ${ }^{7}$ Another review showed that it took between two weeks and 12 months for patients to experience a complete resolution of symptoms after either drug was discontinued. ${ }^{8}$ In the current case, the patient had low ACTH and morning cortisol levels and a subnormal response to synthetic ACTH. This confirmed the diagnosis of secondary adrenal insufficiency. Moreover, the recovery of the hypothalamic-pituitary-adrenal axis after the withdrawal of fluticasone propionate established the cause of the adrenal insufficiency to be a drug-drug interaction.

In the present case, the patient initially reported symptoms of adrenal suppression four years after the concurrent use of fluticasone propionate and ritonavir 
was initiated; however, it is difficult to ascertain when the symptoms first appeared. In addition, although the resolution of the symptoms of adrenal insufficiency occurred within four weeks of discontinuing fluticasone propionate and initiating hydrocortisone treatment, it took 11 months for the full recovery of function of the pituitary and adrenal glands. The replacement of lopinavir/ritonavir with another ARV drug which does not inhibit the CYP 3A4 pathway, such as raltegravir, would have been an alternative management strategy. ${ }^{15}$ However, in view of the patient's history of virological failure with non-nucleoside reverse transcriptase inhibitor-based HAART, ritonavir-boosted protease inhibitors were continued to ensure control of the HIV infection. Fortunately, the patient's asthma symptoms did not deteriorate after the withdrawal of fluticasone propionate and he did not require an inhaled steroid. Notably, no phenotypic changes indicative of Cushing's syndrome were observed at the time of the initial diagnosis of adrenal insufficiency. The treating physician might have mistaken such features, namely central obesity and the presence of a dorsocervical fat pad, to be those of ARV-induced lipodystrophy. ${ }^{7,8}$

To the best of the authors' knowledge, this is the first case of secondary adrenal insufficiency as a result of concomitant ritonavir and inhaled fluticasone propionate reported from the Middle East and North African region. The Joint United Nations Programme on HIV/AIDS has advocated for a treatment target of 90\% of all HIV-infected people to receive antiretroviral therapy (ART) by 2020; it is therefore likely that the use of ART in this region will increase as the deadline for this target approaches. ${ }^{16}$ This expansion of ART provision will require support and vigilance from both pharmacists and HIV physicians in order to avoid serious drug-drug interactions between ART-especially ritonavir-and the medications used to manage other comorbidities. Enhanced communication between HIV clinics and primary healthcare workers is highly recommended to help minimise the frequency of these events. Furthermore, where resources allow, the allocation of an HIVspecialist pharmacist to HIV clinics would ensure that all drug prescriptions are monitored prior to being filled. If this is unfeasible, a more pragmatic approach would be to provide prescribers with a list of common drug-drug interactions and/or access to computerised software to enable drug-drug interaction screening.

\section{Conclusion}

This case highlights the potential for serious drugdrug interactions when prescribing a potent CYP3A4 inhibitor (i.e. ritonavir) with other commonly-used medications that are substrates of the CYP3A4 isoenzyme. It is important that both HIV care providers and primary care physicians are aware of this risk to minimise the occurrence of such events.

\section{References}

1. Gueler A, Moser A, Calmy A, Günthard HF, Bernasconi E, Furrer $\mathrm{H}$, et al. Life expectancy in HIV-positive persons in Switzerland: Matched comparison with general population. AIDS 2017; 31:427-36. doi: 10.1097/QAD.0000000000001335.

2. Abbott Laboratories. Prescribing information for NORVIR. From: www.rxabbvie.com/pdf/norvirtab_pi.pdf Accessed: Apr 2017.

3. Hsu A, Granneman GR, Bertz RJ. Ritonavir: Clinical pharmacokinetics and interactions with other anti-HIV agents. Clin Pharmacokinet 1998; 35:275-91. doi: 10.2165/00003088199835040-00002

4. von Moltke LL, Greenblatt DI, Grassi JM, Granda BW, Duan SX, Fogelman SM, et al. Protease inhibitors as inhibitors of human cytochromes P450: High risk associated with ritonavir. J Clin Pharmacol 1998; 38:106-11. doi: 10.1002/j.1552-4604.1998. tb04398.x

5. Winkler J, Hochhaus G, Derendorf H. How the lung handles drugs: Pharmacokinetics and pharmacodynamics of inhaled corticosteroids. Proc Am Thorac Soc 2004; 1:356-63. doi: 10.1513/pats.200403-025MS.

6. Mackie A, Ventresca GP, Fuller RW, Bye A. Pharmacokinetics of intravenous fluticasone propionate in healthy subjects. $\mathrm{Br}$ J Clin Pharmacol 1996; 41:539-42. doi: 10.1046/j.1365-2125. 1996.36110.x.

7. Epperla N, McKiernan F. Iatrogenic Cushing syndrome and adrenal insufficiency during concomitant therapy with ritonavir and fluticasone. Springerplus 2015; 4:455. doi: 10.1186/s40064015-1218-x.

8. Foisy MM, Yakiwchuk EM, Chiu I, Singh AE. Adrenal suppression and Cushing's syndrome secondary to an interaction between ritonavir and fluticasone: A review of the literature. HIV Med 2008; 9:389-96. doi: 10.1111/j.14681293.2008.00579.x

9. Chen F, Kearney T, Robinson S, Daley-Yates PT, Waldron S, Churchill DR. Cushing's syndrome and severe adrenal suppression in patients treated with ritonavir and inhaled nasal fluticasone. Sex Transm Infect 1999; 75:274.

10. Soldatos G, Sztal-Mazer S, Woolley I, Stockigt J. Exogenous glucocorticoid excess as a result of ritonavir-fluticasone interaction. Intern Med J 2005; 35:67-8. doi: 10.1111/j.14455994.2004.00723x

11. Gillett MJ, Cameron PU, Nguyen HV, Hurley DM, Mallal SA. Iatrogenic Cushing's syndrome in an HIV-infected patient treated with ritonavir and inhaled fluticasone. AIDS 2005; 19:740-1. doi: 10.1097/01.aids.0000166102.21391.81.

12. Samaras K, Pett S, Gowers A, McMurchie M, Cooper DA. Iatrogenic Cushing's syndrome with osteoporosis and secondary adrenal failure in human immunodeficiency virusinfected patients receiving inhaled corticosteroids and ritonavirboosted protease inhibitors: Six cases. J Clin Endocrinol Metab 2005; 90:4394-8. doi: 10.1210/jc.2005-0036.

13. Nocent C, Raherison C, Dupon M, Taytard A. Unexpected effects of inhaled fluticasone in an HIV patient with asthma. J Asthma 2004; 41:793-5. doi: 10.1081/JAS-200038366.

14. Johnson SR, Marion AA, Vrchoticky T, Emmanuel PJ, LujanZilbermann J. Cushing syndrome with secondary adrenal insufficiency from concomitant therapy with ritonavir and fluticasone. J Pediatr 2006; 148:386-8. doi: 10.1016/j. jpeds.2005.11.034. 
15. Martínez E, Larrousse M, Llibre JM, Gutiérrez F, Saumoy M, Antela A, et al. Substitution of raltegravir for ritonavirboosted protease inhibitors in HIV-infected patients: The SPIRAL study. AIDS 2010; 24:1697-707. doi: 10.1097/ QAD.0b013e32833a608a.
16. UNAIDS. 90-90-90: An ambitious treatment targets to help end the AIDS epidemic. From: www.unaids.org/sites/default/ files/media_asset/90-90-90_en_0.pdf Accessed: Apr 2017. 